$$
\begin{aligned}
& -\frac{3}{4} C K^{2} M \frac{1}{A-2 B-(\dot{2} p-q)^{2}} \cos (2 p-q) t \\
& -\frac{3}{4} C K^{2} M \frac{1}{A-2 B-(2 p+q)^{2}} \cos (2 p+q) t \\
& -\frac{1}{4} C M^{3}-\frac{1}{A-2 B-9 q^{2}} \cos 3 q t \\
& +2 G M^{2} \frac{1}{A-2 B}+2 G M^{2} \frac{\cdot 1}{A-2 B-4 q^{2}} \cos 2 q t \\
& +m \cos (q t+\varphi)
\end{aligned}
$$

(7) ベキ級数の形の解 短絡管流が可なり大きくて 限界雷流 $I_{\text {er }}$ に近い場合等に対し笑は, 初めの一振れ で雪䠌がごく近くよるから，時間 $t$ のごく短い範团 内で啇用できる公式を作っておく方が便利ではる。 の目的のために，微分方程式 (8) の解をべキ級数に 展開し下記のごとき数式を得た。

$$
\begin{aligned}
& Y_{1}=Y_{0}+m t^{2}+n t^{4}+s t^{6}+\cdots \cdots \cdots \\
& Y_{2}=Y_{0}+m^{\prime} t^{2}+n^{t} t^{4}+s^{\prime} t^{6}+\cdots \cdots \cdots
\end{aligned}
$$

但し

$$
\begin{aligned}
& m=\frac{3 g a}{4 w d^{\prime}}, \quad n=-\frac{T_{n}}{w L^{2}}\left[1+\frac{16}{3}\left(\frac{A E}{T_{0}}\right)\left(\frac{Y_{0}}{L}\right)^{2}\right] m \\
& s=-\frac{2 g}{5 v L^{2}}\left[\left(\frac{8 E A}{3 L^{2}}+2 Y_{0}\right) Y_{0} m^{2}\right. \\
& \left.+\left(T_{0}+\frac{16}{3} \frac{A E}{L^{2}} Y_{0}^{2}\right) n\right]+\frac{a k g}{5 w d^{3}} m^{2} \\
& m^{\prime}=-m, \quad n^{\prime}=-n \\
& s^{\prime}=-\frac{2 g}{5 w L^{2}}\left[\left(\frac{8 E A}{3 L^{2}}+2 Y_{0}\right) Y_{0} m^{2}\right. \\
& \left.-\left(T_{0}+\frac{16}{3} \frac{A E}{L^{2}} Y_{0}^{2}\right) n\right]-\frac{a k g}{5 w d^{3}} m^{2}
\end{aligned}
$$

（附言）以上の榙計算に対し数字例を示すべきであ るが, 紙数等の関係もむり，後の機会にこれをゆずる

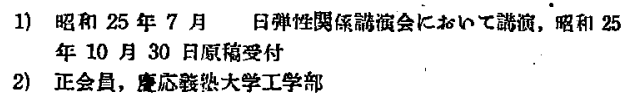

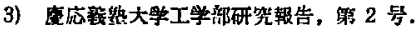

\title{
Graphical Method for Studying Steady Forced Vibrations of Non-Linear Systems.*
}

By Nobuhei Hukuo

Faculty of Engineering Osaka University.

Summary. Steady forced vibrations of arbitrary nonlinear systems are reduced to self-excited vibrations of modified systems through a process of successive approximations. The process converges rapidly. In this paper, some interesting results for non-linear systems are obtained by applying this method.

\section{Introduction.}

$E$-function method ${ }^{1)}$ for solving non-linear vibration problems of one-degree-of-freedom, published previously, is a very convenient one for free and self-excited vibrations. But, in the case when we need to obtain only steady states of forced vibrations, the method does not seem to be so convenient. Therefore, the auther offers a simple, accurate, and practical method, combining $E$-function method with Rauscher's.')

\section{General Procedure.}

The equation of motion in non-linear systems of one-degree-of-freedom is, in general, represented by

$$
\begin{aligned}
\ddot{x}+f(x, \dot{x}) & +g(x)=p(\omega t) \equiv \sum_{n} p_{n} \sin n \omega t \\
& +\sum_{n} q_{n} \cos n \omega t,
\end{aligned}
$$

\footnotetext{
* Peported at the Meeting of Japan Soc. for Appl. mech., May 6. 1950.
}

where, $-g(x)$ is the elastic force, $-f(x ; \dot{x})$ the damping force, and $p(\omega t)$ the external force.

The $E$-function method is as the following.

The total energy of the vibrating particle is

$$
E=\left(1 / 2 \dot{x}^{2}+\int_{0}^{x} g(x) d x .\right.
$$

Differentiating equation (2) with respect to $x$,

$$
d E / d x \equiv E^{\prime}=\ddot{x}+g(x) \text {. }
$$

Therefore the following equation must be satisfied :

$$
E^{\prime}=p(\omega t)-f(x, \dot{x}) .
$$

Both in $E-x$ plane which is constructed by the equation (2) as shown in Fig.1, and in $x-t$ plane, we can simultaneously obtain graphs of $E^{\prime}, E(x)$ and $x(\omega t)$, using the equation (4), through a process of successive approximation in small successive interval of $\dot{x}$ step by step from a given initial con diton. 3) Thereby, $E^{\prime}$ expressed by the equation (4) can always be treated as a function of $\dot{\xi}$ alone.

On the other hand, in our method, the range of the successive approximation is prolonged to one period of the steady vibrations.

Steady forced vibrations are reduced to self-excited vibrations of the same amplitude. The reduction is accomplished by changing $[p(\omega t)-f(x, \dot{x})]$ from 
time, displacement, and velocity function into a velocity function $F(\dot{x})$ through the assumption that $\dot{x}, x$, and $t$ are related as in a approximate sqlution. To the $F(\dot{x})$, there corresponds a new selfexcited motion, which in turn furnishes a second approximation for the relation between $\dot{x}, x$, and $t$, and hence a new function $F(\dot{x})$. Then a new selfe-xcited motion; and the cycle is repeated until the relation between $\dot{x}, x$, and $t$ ceases to change. The frequency of steady forced motion at the assumed amplitude is then known. .

The following is such a procedure.

(A). Give the 0 th approximation $x_{0}\left(\omega_{0} t\right)$ whose positive maximum displacement is a given value $X .^{4}$ )

(B). Equate the periods of $p(\omega t)$ to that of $x_{0}\left(\omega_{0} t\right)$, i. e., put $\omega=\omega_{0}$ in $p(\omega t) .5$ )

(C). Calculate the energy $W_{f, o}$ dissipated by damping force $f\left(x_{0}, \dot{x}_{0}\right)$ over each cycle of the motion $x_{0}\left(\omega_{0} t\right)$.

(D). Calculate the energy $W_{p, 0}$ put into the system by external force $p\left(\omega_{0} t\right)$ over each cycle of the motion $x_{0}\left(a_{0} t\right)$. In this, following $\varphi_{0}$ is included.

(E). Determine the phase angle $\varphi_{0}$ between $x(\omega, t)$ and $p\left(\omega_{0} t\right)$ from the relation $W_{p, 0}=\dot{W}_{f, 0}$ which needs to be satisfied because of the steady state.

(F). Obtain $E_{0}^{\prime}=p\left(\omega_{0} t\right)-f\left(x_{0}, \dot{x}_{0}\right)$ as a function of $\dot{x}$ alone, graphically, i. e., get $E_{0}{ }^{\prime}=F_{0}\left(\dot{x}_{0}\right)$.

(G). Obtain $E_{0}(x)$, of which positive maximum displacement is $X$. using $E_{0}^{\prime}=F_{0}\left(\dot{x}_{0}\right)$ in the $E-x$ plane.

(H). Obtain 1 st approximation $x_{1}\left(\omega_{1} t\right)$ from $E_{0}(x)$.

(I). Repeat steps (B)-(H) until $x_{m}\left(\omega_{m} t\right)$ and $\varphi_{m}$ etc. cease to give different results.

Then; $x_{m}\left(\omega_{m} t\right)$ and $\varphi_{m}$ satisfy the steady solution, its positive maximum displacement being a picked value $X$.

To each amplitude $X$ picked, there will correspond one or two motions, each with a particular frequency.

\section{Each Step.}

Arrangement (a). Let us measure the time $t$ from the moment $x=X$, for convenience" sake, then equation (1) is represented as the followiog:

$$
\begin{aligned}
& \ddot{x}+f(x, \dot{x})+g(x)=-p(\omega t, \varphi) \\
& =\sum_{n} p_{n} \sin n(\omega t+\varphi)+\sum_{n} q n \cos n(\omega t+\varphi)
\end{aligned}
$$

In Fig. 1, point $A$ is the origin of $t$ for, equation (1), point $O^{\prime}$ is for equation (5), and $\overline{O^{\prime} A}$ corres- ponds to $\varphi$.

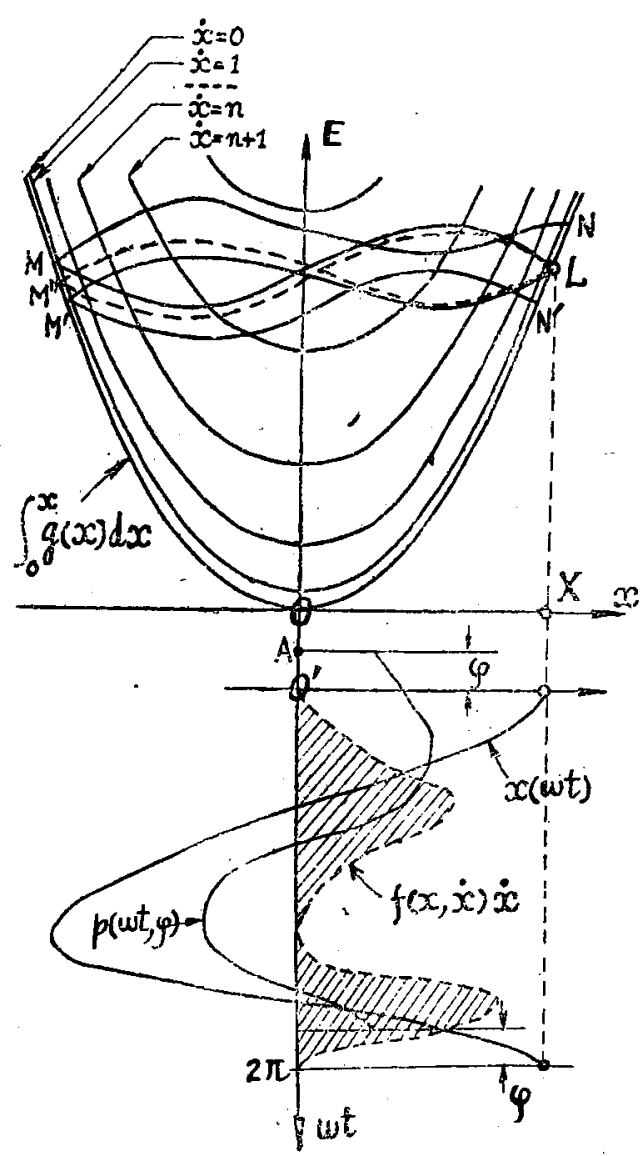

Fig. 1

Arrangement (b). Draw $E-x$ plane and $x-t$ plane, as shown in Fig. 1, by $E$-function method.

(A). Pick out a 0 th approxiamation,

$$
\begin{gathered}
x_{0}\left(\omega_{0} t\right)=a_{0,0}+\sum_{n} a_{n, 0} \sin n \omega_{0} t \\
+\sum_{n} b_{n, 0} \cos n \omega_{0} t
\end{gathered}
$$

from the followings:

(a). Free vibration

(b). An analytical or graphical approximate solution

(c). A known solution for the neighbouring value of $X, \omega$ or the other parameter included in the equation (5).

And then draw it in the $x-t$ plane.

$$
\text { (C). } \begin{aligned}
W_{\gamma, 0} & =\int_{w_{0} t=0}^{w_{0} t=2 \pi} f\left(x_{0}, \dot{x}_{0}\right) d x_{0} \\
& =\int_{0}^{2 \pi / w_{0}} f\left(\dot{x}_{0}, \dot{x}_{0}\right) \dot{x}_{0} d t .
\end{aligned}
$$

Find $x_{0}$ and $\dot{x}_{0}$ as a function of $t$ in $E-x$ plane, and $x-t$ plane, and draw $f\left(x_{0}, \dot{x}_{0}\right) \dot{x}_{0}$ in $x-t$ plane as shown in Fig. 1. The area closed by $t$ and 
$f\left(x_{0}, \dot{x}_{0}\right) \dot{x}_{0}$ is equivalent to $W_{f, 0}$. Calculate the area graphically or with a planimeter.

$$
\text { (D) } \begin{aligned}
W_{p, 0} & =\int_{w_{0} t=0}^{w_{0} t=2 \pi} p\left(\omega_{0} t, \varphi_{0}\right) d x_{0} \\
& =\int_{0}^{2 \pi / w_{0}} p\left(\omega_{0} t, \varphi_{0}\right) \dot{x}_{0} d t .
\end{aligned}
$$

Substitute equations (5) and (6) in equation (8), then we have

$$
\begin{aligned}
W_{p, 0}= & \pi\left[\sum_{n} n\left(a_{n, 0} q_{n}-b_{n, 0} p_{n}\right) \cos n \varphi_{0}\right. \\
& \left.+\sum_{n} n\left(a_{n, 0 p_{n}}+b_{n, 0} q_{n}\right) \sin n \varphi_{0}\right] .
\end{aligned}
$$

(E). Generally, $\varphi_{0}$ can not be calculated immediately from the equation $W_{p, 0}=W_{f, 0}$. Therefore, get firstly $\varphi_{0,1}$, Ist approximation of $\varphi_{0}$, from the following equation :

$$
\begin{aligned}
& \varphi_{0,1}=\sin ^{-1}\left[W_{f, 0} / \pi \sqrt{\left(a_{1,0}-b_{1,0} p_{1}\right)^{2}+\left(a_{1}, 0 p_{1}\right.}\right. \\
& \left.+b_{1,0 q_{1}}\right)^{2}-\tan ^{-1}\left\{a_{1}, 0 q_{1}-b_{1,0} p_{1}\right) /\left(a_{1,0} p_{1}\right. \\
& \left.\left.\left.+b_{1,0} q_{1}\right)\right\}\right] \text {, }
\end{aligned}
$$

in which $a_{n, 0}, b_{n, 0}, p_{n}, q_{n}$ for $n \geq 2$ are neglected because they are small compared with $a_{1,0}, b_{1,0}, p_{1}, q_{1}$. Nextly we can calculate $\varphi_{0}$ from $\varphi_{0,1}$ by interpolation.

Since two values are obtained from the term $\sin ^{-1}$ in equation (10), we need to adopt one of them according to the following rules.

Obtain the free vibrations $x=\sum_{n} k_{n} \cos n \omega t$ from the equation $\ddot{x}+g(x)=0$ by $E$-function method, and draw $k_{1}-\omega$ curve whose abscissa is $\omega$ and ordinate $k_{1}$. When the point $\left(\sqrt{a^{2}{ }_{1,0}+b^{2}{ }_{1,0}}, \omega\right)$ is positioned to the left side of $k_{1}-\omega$ curve, adopt the value of $\sin ^{-1}$ larger than $\pi / 2$, and when the point is to the right, adopt it smaller than $\pi / 2$. When the point is positioned in the vicinity of $k_{1}-\omega$ curve, calculate two different $\varphi_{0}$ for both values of $\sin ^{-1}$ and apply the process to the both- of these two values of $\varphi_{0}$. For $[\mathrm{a}]$ both, $[\mathrm{b}]$ one, or $[\mathrm{c}]$ none, of these two different phase angles, the processes converge. In the case $[a]$, two solutions with particular frequencies are obtained for the given value $X$; in the case $[\mathrm{b}]$, the converging one is a solution; in the case [c], no solution exists for the given value $X$.

(F). As $\varphi_{0}$ is determined,

$$
E_{0}{ }^{\prime}=p\left(\omega_{0} t\right)-f\left(x_{0}, \dot{x}_{0}\right)=F_{0}\left(\dot{x}_{0}\right)
$$

is obtained graphically in $E-x$ and $x-t$ planes.

(G). Draw $E$-curves from the point $x=X$ by equation (11), as shown in Fig.1. Curve LMN is drawn for positive time and curve $L M^{\prime} N^{\prime}$ for nega-

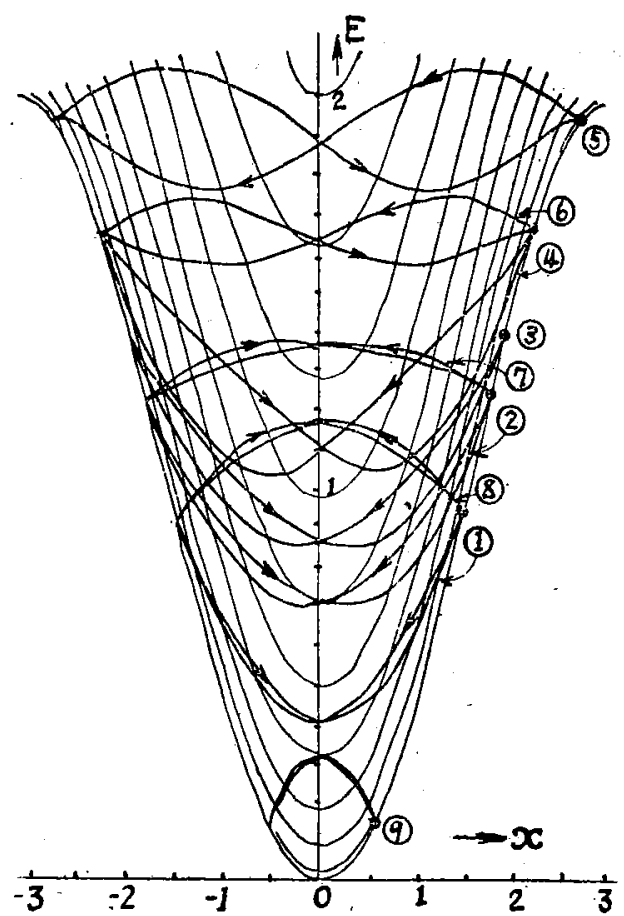

Fig. 2

tive time over one cycle. If $x_{0}\left(\omega_{0} t\right)$ and $\varphi_{0}$ satisfy the steady solution, $\mathrm{LMN}$ coincides with $\mathrm{LM}^{\prime} \mathrm{N}^{\prime}$. In the process of successive approximation, however, the two do not coincide. Therefore, draw $E_{0}(x)$, i. e. $L M^{\prime \prime} N$, along the midway of $L M N$ and $L \dot{M}^{\prime} N^{\prime}$, so as for the $E$-curve starting from $x=X$ to return back to $x=X$ after swinging one cycle.

(H). Tranform $E_{0}(x)$ to $x-t$ curve, then we get the 1 st approximation :

$$
\begin{aligned}
x_{1}\left(\dot{\omega}_{1} t\right)= & a_{0,1}+\sum_{n} a_{n, 1} \sin n \omega_{1} t \\
& +\sum_{n} b_{n, 1} \cos n \omega_{1} t .
\end{aligned}
$$

\section{Accuracy and Convergency.}

As the method is graphical, of course, the accuracy depends upon the size of the graph, the number of the potential curves of equal velocity, etc. But, as far as the author experiences, the error is ordinarily about $0.5 \%$, and it is easy to restrict the error within $0.2 \%$. As the accuracy of this method coincides with that of $E$-function method; details are omitted in this paper.

Despite the convergence of the process depends upon the accuracy of its 0 th approximation, the repetitions of the cycle of approximation produce only microscopic change in $E_{m}(x), \varphi_{m}$ and $x_{m}\left(\omega_{m} t\right)$ when $m$ becomes 3-5.

V. Stability ${ }^{()}$ 
Both stable and unstable solutions can be obtained by this method. By drawing transient vibrations in the neighbourhood of the obtained solutions by $E$-function method we can determine its stability.

\section{V1. Applications and Results.}

This method. is applied to the non-linear system, in which sinusoidal force acts on a simple pendulum with viscous damping, the equation of motion being

$$
\ddot{x}+\lambda \dot{x}+\sin x=P \cos \omega t \text {. }
$$

The error of the following results is less than about $0.5 \%$.

Table 1 indicates the free vibrations $x=\sum_{n} k_{n} \cos \omega t$ obtained from the equation $\ddot{x}+\sin x$ $=0$, where the time $t$ is measured from the moment of the system's extreme displacement on the positive side.

Table 2 is the result of the forced vibaration :

$$
\ddot{x}+0.5 \dot{x}+\sin x=0.8 \cos \omega t \text {. }
$$

The steady solutions of this equation are represented by $x=\sum_{n} \alpha_{n} \cos n\left(\omega t+\phi_{n}\right), \omega, \alpha_{n}, \phi_{n}$ in this equation and $X, \varphi$ are indicated in Table 2 .

$E$ - and $F(\dot{x})-\dot{x}$ curves are shown in Figs 2 and 3 , their numbers corresponding to those in Table 2. As $F(\dot{x})-\dot{x}$ curve must be an ellipse in the case of linear system, the deviation from the ellipse in Fig. 3 represents the non-linearities.

Table 1

\begin{tabular}{c|c|c|c|c|c}
\hline $\begin{array}{c}\text { maximum } \\
\text { displacement }\end{array}$ & $\omega$ & $k_{1}$ & $k_{3}$ & $k_{5}$ & $k_{7}$ \\
\hline 1.000 & .938 & 1.010 & -.010 & - & - \\
1.500 & .861 & 1.514 & -.026 & - & - \\
2.000 & .752 & 2.044 & -.064 & .002 & - \\
2.200 & .707 & 2.278 & -.082 & .004 & - \\
2.400 & .641 & 2.512 & -.108 & .010 & - \\
2.600 & .574 & 2.754 & -.164 & .016 & - \\
2.800 & .495 & 3.012 & -.234 & .028 & -.006 \\
3.000 & .389 & 3.348 & -.396 & .066 & -.018 \\
3.100 & .325 & 3.590 & -.590 & .138 & -.070 \\
\hline
\end{tabular}

Fig. 4 shows the relations between $\omega$ and $X, \alpha_{1}$, $\bar{\alpha}_{1}, k_{1}, \alpha_{3}$, and between $\omega$ and $\varphi, \phi_{1}, \bar{\phi}_{1}$; Fig. 5 . the relations between $\omega$ and $\alpha_{3}, \bar{\alpha}_{3}, \alpha_{5}$, and between $\omega$ and $\phi_{3}, \bar{\phi}_{3}, \phi_{5} ;$ where $\bar{\alpha}_{1}, \bar{\alpha}_{3}, \bar{\phi}_{1}$, and $\bar{\phi}_{3}$ are results of analytsc approximations obtained by $M$. Tumura ${ }^{7)}$.

From these, following interesting characteristics for non-linear systems can be established.

All $\alpha_{n}-\omega$ and $\phi_{n}-\omega$ curves have similar figures, and all $d \alpha_{n} / d \omega$ and $d \phi_{n} / d \omega$ become infinity simultaneously at the same values of $\omega$. And the points, at which $d \alpha_{n} / d \omega$ and $d \phi_{n} / d \omega$ become infinity, distribute on the boundary between stable and unstable.

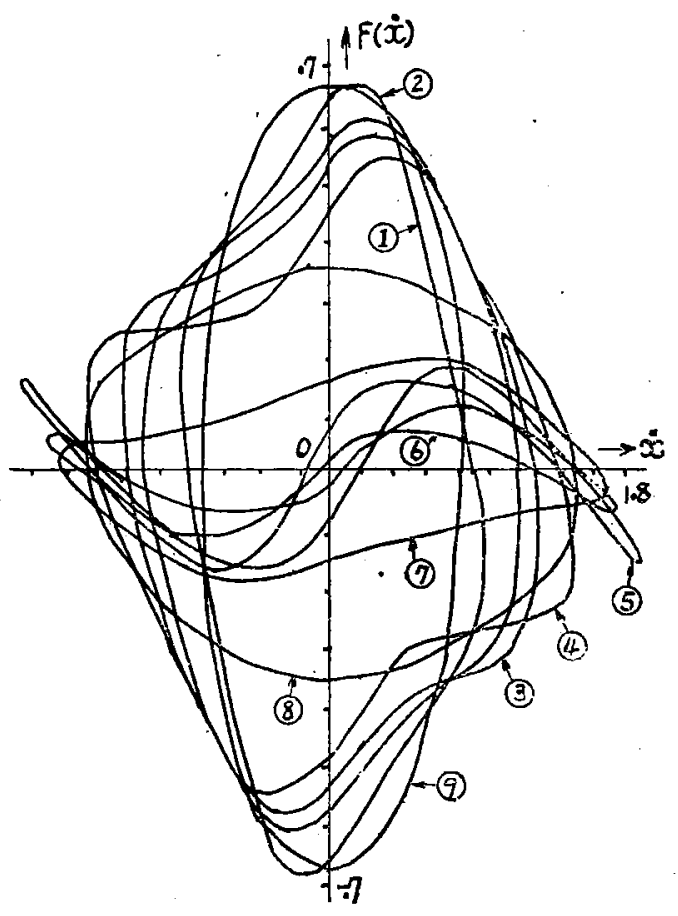

Fig. 3

\begin{tabular}{|c|c|c|c|c|c|c|c|c|c|c|}
\hline number & $X$ & $\omega$ & $-\varphi$ & $\alpha_{1}$ & $\phi_{1}$ & $\alpha_{3}$ & $\phi_{3}$ & $a_{5}$ & $\phi_{5}$ & stability \\
\hline $\begin{array}{l}9 \\
8 \\
7 \\
6\end{array}$ & $\begin{array}{l}0.540 \\
1.500 \\
1.800 \\
2.290 \\
2.660\end{array}$ & $\begin{array}{r}1.510 \\
.960 \\
.843 \\
.655 \\
.551\end{array}$ & $\begin{array}{l}2.572 \\
1.972 \\
1.769 \\
1.631 \\
1.658\end{array}$ & $\begin{array}{r}.539 \\
1.517 \\
1.841 \\
2.391 \\
2.819\end{array}$ & $\begin{array}{l}2.609 \\
2.005 \\
1.760 \\
1.571 \\
1.571\end{array}$ & $\begin{array}{l}.013 \\
.033 \\
.096 \\
.180\end{array}$ & $\begin{array}{r}-. .-007 \\
5.849 \\
4.849 \\
4.622 \\
4.604\end{array}$ & $\begin{array}{l}\overline{.} \\
.004 \\
.018 \\
.031\end{array}$ & $\begin{array}{l}1 . \overline{769} \\
1.538 \\
1.482\end{array}$ & $\begin{array}{l}\text { stable } \\
\text { stable } \\
\text { stable } \\
\text { stable } \\
\text { stable }\end{array}$ \\
\hline $\begin{array}{r}85 \\
1 \\
82\end{array}$ & $\begin{array}{l}2.800 \\
1.020 \\
1.500 \\
1.700 \\
1.800\end{array}$ & $\begin{array}{l}.517 \\
.300 \\
.532 \\
.560 \\
.560\end{array}$ & $\begin{array}{r}1.673 \\
.420 \\
.619 \\
.719 \\
.782\end{array}$ & $\begin{array}{l}2.988 \\
1.046 \\
1.535 \\
1.782 \\
1.833\end{array}$ & $\begin{array}{r}1.571 \\
.175 \\
.557 \\
.679 \\
.729\end{array}$ & $\begin{array}{l}.210 \\
.096 \\
.051 \\
.076 \\
.083\end{array}$ & $\begin{array}{r}4.612 \\
.830 \\
3.499 \\
3.716 \\
3.766\end{array}$ & $\begin{array}{r}.034 \\
.012 \\
.005 \\
.003\end{array}$ & $\begin{array}{r}1.516 \\
3.552 \\
.481 \\
.550\end{array}$ & $\begin{array}{l}\text { stable } \\
\text { stable } \\
\text { stable } \\
\text { stable } \\
\text { unstable }\end{array}$ \\
\hline $\begin{array}{l}3 \\
4\end{array}$ & $\begin{array}{l}1.900 \\
2.000 \\
2.300\end{array}$ & $\begin{array}{l}.554 \\
.538 \\
.497\end{array}$ & $\begin{array}{r}.838 \\
.844 \\
1.011\end{array}$ & $\begin{array}{l}1.997 \\
2.096 \\
2.431\end{array}$ & $\begin{array}{l}.773 \\
.804 \\
.917\end{array}$ & $\begin{array}{r}.092 \\
.103 \\
.172\end{array}$ & $\begin{array}{l}3.788 \\
3.826 \\
3.946\end{array}$ & $\begin{array}{l}.009 \\
.006 \\
.017\end{array}$ & $\begin{array}{l}.568 \\
.844 \\
.854\end{array}$ & $\begin{array}{l}\text { unstable } \\
\text { unstable } \\
\text { nustable }\end{array}$ \\
\hline
\end{tabular}

Table 2. 

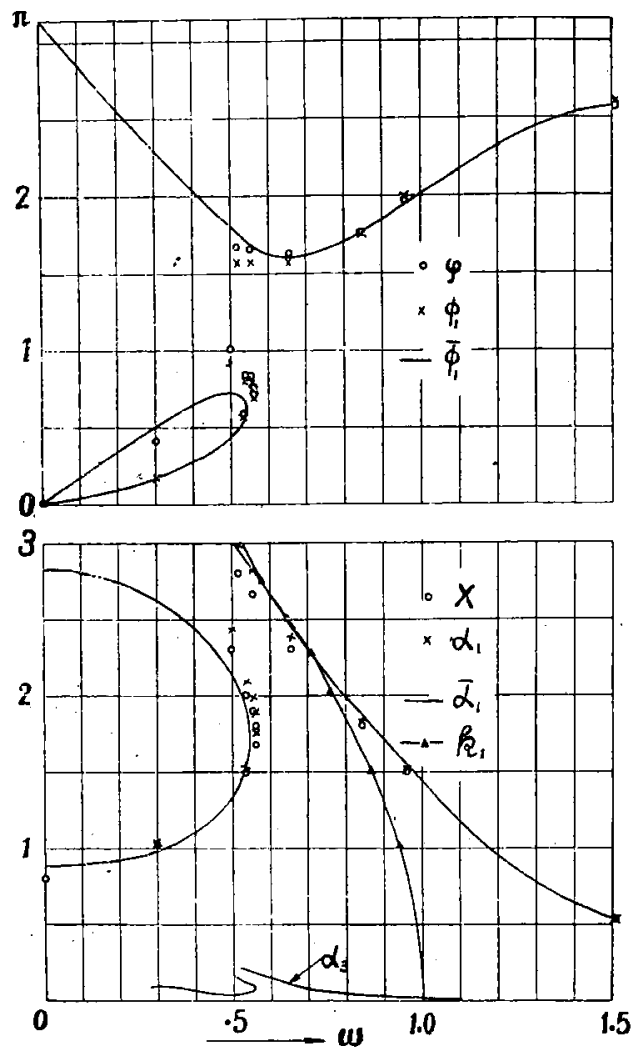

Fig. 4

The amplitude of 3rd harmonics becomes large at $\omega \doteqdot 0.3$. This means the resonance of $3 \mathrm{rd}$ harmonics. Namely, it suggests the possibility of the "resonance of higher harmonics".

\section{ACKNOWLEDGEMENT}

The author wishes to acknowledge the encouragement and suggestions which were recieved from Prof. Kenzo Jō, Faculty of Engineering, Osaka University.

REFERENCES

1) M. Tumura, S. Makinouti \& N. Hukuo: Trans. of the
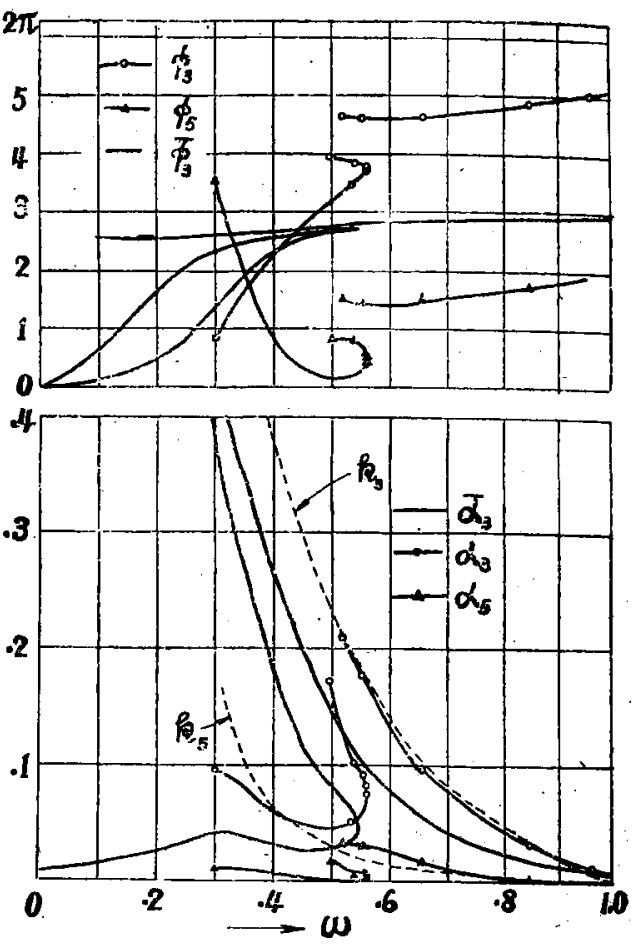

Fig. 5

Japan Soc. of Mech. Engr., 17, 57 (1951), pp. 69-80. 2) Fifth Intern. Congr. for Appl. Mech. (1938) : Trans A. S.M.E., 60 (1939) .

3) For the free vibration, $E(x)$-curve is a straight line through the point corresponding to the initial condition in $E-x$ plane because $E^{\prime}=0$.

For the self-excited vibration, the successive approximation is much more simpler than that for the forced vibration, because $E^{Y}$ does not contain the time function $p(\omega t)$. Moreover, in the case when $E^{\prime}$ is a function of $\dot{x}$ alone, i. e. $E^{\prime}=f(\dot{x})$, the successive approximation is not necessary.

4) According to the object, we may adopt any most cover nient one from among $\left(x=X \cdot \dot{x}=v_{0}\right)$, in place of the positive maximum displacement $X$ i. e, $(x=X, \dot{x}=0)$.

5) For subharmonic vibrations of order $v$, put $p\left(v w_{0} t\right)$, where $v$ is a positive integer.

6) Rauscher's criterion for stability is not rigorous.

7) Technology Reports of the Osaka University, Vol. 1 (1951) and Vol. 2 (1952).

\title{
Some Notes on the Plastic Deformation of Hollow Spheres with Large Strain (2 nd Report) Theory of Unloading ${ }^{1)}$
}

\author{
By Hisao $\mathrm{M}_{\mathrm{II}}{ }^{\mathrm{l})}$, Member
}

\section{Introduction}

As the continuation of former paper ${ }^{3}$ ) the theory of unloading, to which belong the problems in what manner the loaded sphere deforms and how the stress distribution in it varies with the reduction of pressures, has been developed. In this, the re- covering strains are also considered to be finite and furthermore, similar to the case of loading process, the law of plastic deformation which the material is to obey in the unloading process is again taken as the "Maximum Shear Stress Theory" in which the recovering maximum principal stress difference being 